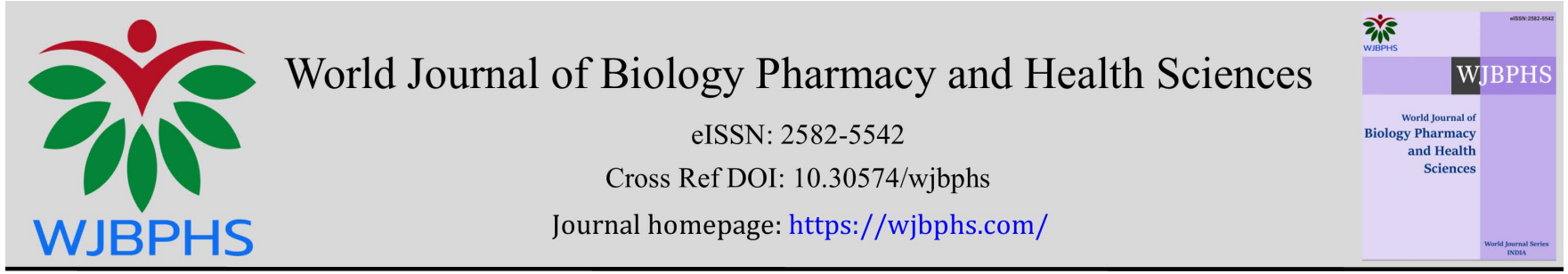

(CASE REPORT)

\title{
Electrophysiological and behavioral evaluation of auditory processing before and after speech therapy intervention in children after traumatic brain injury: Case reports
}

\author{
Antoniaci Mariane Richetto da Silva ${ }^{1}$, Andrade Adriana Neves de 2, Suriano Italo Capraro ${ }^{3}$, Avila Clara \\ Regina Brandão de ${ }^{4}$ and Gil Daniela ${ }^{5, *}$ \\ ${ }^{1}$ Mariane Richetto da Silva Antoniaci. Speech Therapy Department. Universidade Federal de São Paulo. São Paulo, Brazil. \\ ${ }_{2}^{2}$ Adriana Neves de Andrade. Speech Therapy Department. Universidade Federal de São Paulo. São Paulo, Brazil. \\ 3 Italo Capraro Suriano. Department of Neurology/Neurosurgery, Universidade Federal de São Paulo. São Paulo, Brazil. \\ ${ }^{4}$ Clara Regina Brandão de Avila. Speech Therapy Department. Universidade Federal de São Paulo. São Paulo, Brazil. \\ ${ }_{5}^{5}$ Daniela Gil. Speech Therapy Department. Universidade Federal de São Paulo. São Paulo, Brazil.
}

World Journal of Biology Pharmacy and Health Sciences, 2021, 05(03), 064-074

Publication history: Received on 05 February 2021; revised on 07 March 2021; accepted on 10 March 2021

Article DOI: https://doi.org/10.30574/wjbphs.2021.5.3.0025

\begin{abstract}
Objectives: to verify the effects of a speech therapy intervention program in children after moderate and severe traumatic brain injury using electrophysiological and behavioral assessment of central auditory processing.

Method: Five children aged 9 to 11 years old who suffered closed brain trauma of moderate or severe degree for at least 6 months, right-handed, literate before the injury, diagnosed with Central Auditory Processing and Reading and Writing Disorders. Ten speech therapy intervention sessions were held, covering the area of language and auditory training activities. Children were submitted to electrophysiological evaluation with Long Latency Auditory Evoked Potential and behavioral assessment of central auditory processing, pre and post intervention.

Results: Statistically significant, after speech therapy intervention, in the LLAEP with tone burst, there was an improvement in the latencies of the N2 component in both ears and P3 in the right ear. CAPD improves the memory test for verbal sounds in sequence and the speech test with white noise in the right ear.

Conclusion: After the speech therapy intervention program in individuals with TBI it was observed: reduction of the latency of the N1 component in the left ear, in the LLAEP with tone burst; reduction of the latencies of the components N1, P2 and N2 in the right and left ears, and for the latency of the P3 only in the right ear, in the LLAEP with complex stimuli and performance improvement in the behavioral tests of central auditory memory processing for verbal sounds in sequence and speech with white noise.
\end{abstract}

Keywords: Craniocerebral Trauma; Child; Auditory Perception; Communication Disorders; Evoked Potentials; Auditory; Neuronal Plasticity

\section{Introduction}

Traumatic brain injury (TBI) basically results from physical aggressions on the skull and its content, the injuries can be caused by the impact and the acceleration/deceleration movement of the brain inside the cranial box [1]. TBI comprises one of the most common causes of child trauma, corresponding to high rates of hospitalization, with significant morbidity and mortality indices [2].

\footnotetext{
* Corresponding author: Gil Daniela

Daniela Gil. Speech Therapy Department. Universidade Federal de São Paulo. São Paulo, Brazil.

Copyright (C) 2021 Author(s) retain the copyright of this article. This article is published under the terms of the Creative Commons Attribution Liscense 4.0.
} 
Among the sequelae of traumatic brain injuries, one can include seizures, depression and anxiety, post-traumatic stress, headaches/migraines, sleep disorders, cognitive and/or social dysfunction, behavioral changes, changes in auditory and visual pathways [3]. Changes in the auditory and vestibular systems can occur at the peripheral and/or central level, and include hearing loss, central auditory processing disorder, tinnitus, dizziness/vertigo, phonophobia, photophobia and auditory hallucinations [3].

Due to the high incidence of auditory alterations in individuals with TBI, for the precise audiological diagnosis, the assessment must include behavioral procedures (pure tone and speech audiometries and behavioral evaluation of central auditory processing), electroacoustic procedures (tympanometry, acoustic reflexes, evoked otoacoustic emissions and suppression of otoacoustic emissions) and electrophysiological tests (short, middle and/or long latency auditory evoked potentials) $[3,4,5,6]$.

Basic audiological evaluation (pure tone and speech audiometry, tympanometry and acoustic reflexes measures) provides information on auditory sensitivity, auditory performance in situations of ideal hearing, mobility of the ossicular tympanic system and intra- and extra-axial abnormalities of the brainstem [3], and the behavioral assessment of central auditory processing provides an overview of the individual's hearing abilities in adverse hearing situations.

Bearing in mind that $58 \%$ of the subjects after traumatic brain injury may present central auditory processing disorder [3], in addition to the behavioral assessment of the central auditory nervous system, it is also important to perform the Auditory Evoked Potentials (AEP), either for the analysis of the central auditory pathway integrity, monitoring of spontaneous recovery and/or analysis of the effectiveness of therapeutic interventions after TBI [3, 5].

When TBI occurs in the children, brain injuries can generate cognitive changes related to the speed of processing information, maintaining attention, executive functions (reasoning and problem solving), in addition to difficulties in acquiring new concepts and memory stability, which consequently generates low school performance [7]. In view of the above, it is hypothesized that a speech therapy program with an emphasis on hearing rehabilitation could minimize these difficulties and positively influence learning. $[8,9,10]$. Based on the above, this study aims to verify the effects of a speech therapy intervention program in children after moderate and severe TBI in the electrophysiological and behavioral assessment of central auditory processing.

\section{Materials and methods}

This study was registered on Plataforma Brasil, with Presentation Certificate for Ethical Appreciation no. 46059515.5.0000.5505, analyzed and approved by the Research Ethics Committee of Universidade Federal de São Paulo under the number CEP 0700/2015. The research was developed in the Hearing Electrophysiology, Central Auditory Processing and Reading and Writing outpatient clinics of Speech Therapy Department at Universidade Federal de São Paulo in partnership with the Neurology/Neurosurgery outpatient clinic at Universidade Federal de São Paulo.

This is a descriptive, observational, cross-sectional study conducted with children and adolescents who suffered TBI. Before the survey, parents and/or guardians signed the Informed Consent Form and the children signed it for voluntary participation in the study.

For sample recruitment, the following eligibility criteria were listed: age between 8 and 15 years; right hand preference; having suffered moderate or severe closed TBI for at least 6 months, Glasgow Scale of three to thirteen on hospital admission [11], literate and no history of school difficulties before TBI; auditory thresholds within the normal range in both ears [12]; type A tympanometric curves and presence of contralateral acoustic reflexes [13]; referred from the Neurosurgery and Neurotrauma Outpatient Clinic of UNIFESP; presenting language changes after TBI; absence of syndromes and/or evident cognitive impairments. As exclusion criteria, individuals who had previously undergone formal auditory training and/or did not attend all speech therapy intervention sessions were not admitted.

All subjects have undergone auditory electrophysiological and behavioral assessment before and after the speech therapy intervention program.

Electrophysiological evaluation preceded the behavioral evaluation and was performed with Smart EP Plus 2 Channels from Intelligent Hearing System and was recorded in a room with acoustic and electrical treatment. The skin was prepared with abrasive paste and the positioning of the electrodes followed the international system 10-20 [14].

The stimuli of the long latency auditory evoked potentials were tone burst (with frequency of $1000 \mathrm{~Hz}$ for the frequent stimulus and $2000 \mathrm{~Hz}$ for the rare stimulus) and speech (syllable/ba/ the frequent stimulus and the syllable /ga/ the 
rare stimulus), presented in a binaurally at $80 \mathrm{dBnHL}$. Three hundred stimuli were presented, 240 (80\%) for the frequent and $60(20 \%)$ for the rare. Alternating polarity was used, with a stimulus presentation rate of one per second and the filter used was 0.5 to $17 \mathrm{~Hz}$. Two waves were recorded, one for the frequent stimulus and the other for the rare, and at the end the waves were subtracted to mark the P3 wave in the resulting trace. The latency value was considered for the analysis of this potential [15]. The subjects were instructed to keep their attention to the rare stimulus, moving their hand whenever it was noticed. The strategy of moving the hand, instead of mentally counting the rare stimulus was created after a pilot study in which it was observed that patients had difficulties in memorizing and/or counting stimuli mentally.

Behavioral assessment of central auditory processing was performed using the following instruments: acoustic booth, musical instruments, Philips Expanium discman, Grason-Stadler audiometer, model GSI-61, pair of supra-aural headphones model TDH-50P, compact disc with non-verbal (marketed by Auditec Saint Louis) and verbal tests [16] their respective protocols and figures from the book of behavioral auditory tests to assess central auditory processing [16]

The following non-verbal tests were used: Duration Pattern Test- DPT $[17,18]$ and Random Gap Detection Test (RGDT). Duration Pattern Test (DPT) version by Taborga [17] was used for children up to 9 years old. The reference criterion: for 3 tones $100 \%$ of correct answers and for 4 tones a value greater than or equal to $90 \%$ of correct answers regardless of the type of response - humming/naming task [17]. For individuals aged 10 years or older, Duration Pattern Test DPT (Musiek version) was used. For the classification in normal/abnormal, the following reference criteria were adopted: $83 \%$ of correct answers and 76\% correct of correct answers for humming and verbal labeling, respectively [19].

Verbal tests in Brazilian Portuguese were applied and analyzed according to the national standards [16]. The following tests were applied: Word Recognition Score (WRS), Speech Test with White Noise (STWN), Dichotic Consonant Vowel (DCV) test (Free Recall), Staggered Spondaic Word (SSW) test, Pediatric Speech Intelligibility with sentences (PSI) test.

After the initial evaluations, subjects underwent ten speech therapy intervention sessions, lasting 60 minutes each, performed once a week. In all sessions there was stimulation in the area of language and also auditory skills training. The intervention in the language area (reading and writing) followed the proposal of Ávila et al. (2013) [20], addressing the activities of phonological awareness, psychomotor stimulation, oral comprehension, phoneme-grapheme association, memory, rapid naming, flash reading, reading comprehension and written production.

The training of auditory skills was organized in an increasing order of complexity based on the protocol developed by Gil and Marangoni (2014) [5]. The difference between the interventions was that for this study, the auditory stimuli were produced by the computer program Audacity 2.1.2. During the sessions, patients performed auditory activities using earphones and with visual support (pictures and words) for multisensory stimulation. At the end of each session, parents and/or guardians were instructed to perform activities at home, which involved auditory activities, in order to reinforce the content focused in the session.

The results of all evaluations were tabulated and submitted to descriptive (mean, standard deviation, minimum and maximum) and inferential analysis. Comparisons of the pre- and post-intervention results were performed using the Wilcoxon signed-rank test. Comparisons for qualitative analyses were performed using the chi-square test and correlations according to Pearson, for metric data ( $r$ ). The analyses were performed using the statistical software SPSS version 20.3 for Windows. Comparisons with p-value $<0.05$ were considered statistically significant and highlighted with the asterisk symbol $\left(^{*}\right)$.

\section{Results}

Eight children met the eligibility criteria and were selected for the study. Of these, one individual participated in a pilot study and two subjects did not accept to participate in the research. Thus, the final sample consisted of five children (four boys and one girl), aged 9 to 11 years old, attending between the $4^{\text {th }}$ and $6^{\text {th }}$ grades of school. The average of the Glasgow Admission test was 9.6 points ( $\mathrm{SD}=2.19$; minimum $=7$; maximum $=13$ ), the average hospital stay was 33 days $(\mathrm{SD}=18.29 ;$ minimum $=10 ;$ maximum $=60)$ and the average sedation time was 19 days $(\mathrm{SD}=22.95 ;$ minimum = 7; maximum $=60$ ).

The results of the pre and post speech therapy evaluations are presented below.

To visualize the performance of individuals in electrophysiological tests, tables were built with descriptive analyses of the LLAEP components with tone burst before and after speech therapy intervention (Table 1) 
Table 1 Descriptive statistics of latencies and amplitudes of LLAEP components, before speech therapy intervention $(\mathrm{n}=5)$

\begin{tabular}{|l|l|l|l|l|l|l|l|l|}
\hline & \multicolumn{4}{|c}{ Pre-intervention } & \multicolumn{3}{c|}{ Post-intervention } \\
\hline Variable & Minimum & Maximum & Mean & S.D. & Minimum & Maximum & Mean & S.D. \\
\hline N1.LAT.RE & 104.00 & 129.00 & 119.20 & 9.26 & 100.00 & 112.00 & 106.60 & 6.07 \\
\hline N1.LAT.LE & 110.00 & 125.00 & 115.20 & 5.98 & 94.00 & 106.00 & 101.20 & 4.55 \\
\hline P2.LAT.RE & 142.00 & 176.00 & 163.80 & 13.39 & 137.00 & 190.00 & 157.80 & 24.95 \\
\hline P2.LAT.LE & 142.00 & 172.00 & 161.40 & 14.35 & 135.00 & 180.00 & 148.00 & 18.24 \\
\hline P2.AMP.RE & 3.59 & 10.75 & 5.80 & 2.86 & 1.66 & 6.68 & 3.91 & 1.89 \\
\hline P2.AMP.LE & 4.93 & 10.53 & 6.60 & 2.38 & 6.34 & 8.14 & 7.04 & 0.82 \\
\hline N2.LAT.RE & 209.00 & 252.00 & 226.80 & 17.40 & 207.00 & 269.00 & 228.20 & 24.91 \\
\hline N2.LAT.LE & 209.00 & 251.00 & 225.40 & 16.07 & 209.00 & 231.00 & 218.00 & 7.93 \\
\hline P3LATRE & 252.00 & 357.00 & 298.40 & 50.21 & 240.00 & 353.00 & 302.60 & 55.68 \\
\hline P3.LAT.LE & 242.00 & 355.00 & 291.60 & 48.68 & 231.00 & 354.00 & 300.60 & 58.60 \\
\hline P3.AMP.RE & 4.81 & 11.37 & 7.25 & 2.81 & 1.82 & 14.15 & 7.54 & 4.38 \\
\hline P3.AMP.LE & 5.86 & 11.24 & 7.78 & 2.17 & 6.29 & 15.03 & 9.24 & 4.01 \\
\hline
\end{tabular}

Observing the descriptive analysis of the LLAEP components, using tone burst, it was possible to observe a reduction in the latency of the components N1 and P2, and an increase in the amplitude of P2, in both ears, and a reduction in the N2 latency in the left ear, when comparing the pre- and post-intervention moments. To verify whether this difference is statistically relevant, the results were compared using the Wilcoxon test (Table 2).

Table 2 P-values of LLAEP-TB comparisons before and after speech therapy intervention

\begin{tabular}{|l|l|}
\hline Variable & p-value \\
\hline N1.LAT.RE_POSTS - N1.LAT.RE_PRE & 0.080 \\
\hline N1.LAT.LE_POST- N1.LAT.LE_PRE & $0.042^{*}$ \\
\hline P2.LAT.RE_POST - P2.LAT.RE_PRE & 0.686 \\
\hline P2.LAT.LE_POST - P2.LAT.LE_PRE & 0.225 \\
\hline P2.AMP.RE_POST - P2.AMP.RE_PRE & 0.500 \\
\hline P2.AMP.LE_POST - P2.AMP.LE_PRE & 0.500 \\
\hline N2.LAT.RE_POST - N2.LAT.RE_PRE & 0.893 \\
\hline N2.LAT.LE_POST- N2.LAT.LE_PRE & 0.225 \\
\hline P300.LAT.RE_POST - P300.LAT.RE_PRE & 0.893 \\
\hline P300.LAT.LE_POST - P300.LAT.LE_PRE & 0.893 \\
\hline P300.AMP.RE_POST - P300.AMP.RE_PRE & 0.893 \\
\hline
\end{tabular}

Legend: LAT: latency, AMP: amplitude; RE: right ear; LE: left ear; PRE: pre-intervention; POST: post intervention; * statistically significant result

There was a significant difference between the pre- and post-intervention moments only for the N1 latency in the left ear. The same procedures were performed with the LLAEP elicited by complex stimulus (speech). Table 3 presents the descriptive analysis before and after speech therapy intervention. 
Table 3 Descriptive statistics of latencies and amplitudes of LLAEP components with complex stimulus (speech) before and after speech therapy intervention

\begin{tabular}{|l|l|l|l|l|l|l|l|l|l|}
\hline & \multicolumn{3}{|c}{ Pre-intervention } & \multicolumn{3}{c|}{ Post-intervention } \\
\hline Variable & Minimum & Maximum & Mean & S.D. & Minimum & Maximum & Mean & S.D. \\
\hline N1.LAT.RE & 113.00 & 145.00 & 131.40 & 12.54 & 109.00 & 115.00 & 111.40 & 2.51 \\
\hline N1.LAT.LE & 120.00 & 165.00 & 140.80 & 16.33 & 106.00 & 116.00 & 112.00 & 4.24 \\
\hline P2.LAT.RE & 168.00 & 192.00 & 182.20 & 8.96 & 137.00 & 178.00 & 149.40 & 18.39 \\
\hline P2.LAT.LE & 168.00 & 192.00 & 182.20 & 8.73 & 128.00 & 176.00 & 148.40 & 19.30 \\
\hline P2.AMP.RE & 5.75 & 13.60 & 9.08 & 3.20 & 1.66 & 11.83 & 9.05 & 4.22 \\
\hline P2.AMP.LE & 5.94 & 14.95 & 9.72 & 3.58 & 10.01 & 14.82 & 11.64 & 2.08 \\
\hline N2.LAT.RE & 244.00 & 278.00 & 255.20 & 13.81 & 223.00 & 232.00 & 227.00 & 3.81 \\
\hline N2.LAT.LE & 238.00 & 249.00 & 245.20 & 4.71 & 160.00 & 239.00 & 214.00 & 30.92 \\
\hline P3.LAT.RE & 257.00 & 287.00 & 275.00 & 11.38 & 226.00 & 268.00 & 257.00 & 17.78 \\
\hline P3.LAT.LE & 254.00 & 285.00 & 270.40 & 12.42 & 226.00 & 268.00 & 253.40 & 19.28 \\
\hline P3.AMP.RE & 12.83 & 32.96 & 19.36 & 8.63 & 12.80 & 21.67 & 18.27 & 3.32 \\
\hline P3.AMP.LE & 12.74 & 30.73 & 21.02 & 7.89 & 6.29 & 20.99 & 16.20 & 5.81 \\
\hline
\end{tabular}

Legend: LAT: latency, AMP: amplitude, LE: left ear, RE: right ear

In the descriptive analysis of the LLAEP components, using complex stimuli, it was possible to observe a reduction in latency of the components N1, P2 and P3, in both ears, without increasing the amplitude of P3, when comparing the preand post-intervention moments. The results were compared using the Wilcoxon test (Table 4) to verify whether the improvement has statistical significance.

Table 4 P-values of comparisons of LLAEP-complex stimulus before and after speech therapy intervention

\begin{tabular}{|l|l|}
\hline Variable & p-value \\
\hline N1.LAT.RE_POST - N1.LAT.RE_PRE & $0.043^{*}$ \\
\hline N1.LAT.LE_POST - N1.LAT.LE_PRE & $0.043^{*}$ \\
\hline P2.LAT.RE_POST - P2.LAT.RE_PRE & $0.043^{*}$ \\
\hline P2.LAT.LE_POST - P2.LAT.LE_PRE & $0.043^{*}$ \\
\hline P2.AMP.RE_POST - P2.AMP.RE_PRE & 0.686 \\
\hline P2.AMP.LE_POST - P2.AMP.LE_PRE & 0.080 \\
\hline N2.LAT.RE_POST - N2.LAT.RE_PRE & $0.043^{*}$ \\
\hline N2.LAT.LE_POST- N2.LAT.RE_PRE & $0.043^{*}$ \\
\hline P300.LAT.RE_POST - P300.LAT.RE_PRE & $0.043^{*}$ \\
\hline P300.LAT.LE_POST - P300.LAT.LE_PRE & 0.080 \\
\hline P300.AMP.RE_POST - P300.AMP.RE_PRE & 0.893 \\
\hline P300.AMP.LE_POST - P300.AMP.LE_PRE & 0.225 \\
\hline
\end{tabular}

Legend: LAT: latency, AMP: amplitude, LE: left ear, RE: right ear, PRE:pre-intervention, POST: post-intervention; * statistically significant result

There was a statistically significant difference between the results before and after speech therapy intervention for the latencies of the components N1, P2 and N2 in the right and left ears, and for the latency of the component P3 only in the right ear. After presenting the results of the electrophysiological evaluation, the descriptive results of the behavioral evaluation of auditory processing are now presented. The average performance for the RGDT test in the preintervention evaluation was $30.1 \mathrm{~ms}$ (minimum of $5.5 \mathrm{~ms}$, maximum of $100 \mathrm{~ms}$ with standard deviation of 39.66 ) and 
in the post-intervention evaluation of $45.6 \mathrm{~ms}$ (minimum of $2 \mathrm{~ms}$, maximum $207.5 \mathrm{~ms}$ with standard deviation of 90.55 ). The results of the other behavioral tests used, which are analyzed as a percentage of correct answers, are shown in Table 5.

Table 5 Descriptive statistics, presented in percentage, of the behavioral assessment of central auditory processing before and after speech therapy intervention

\begin{tabular}{|c|c|c|c|c|c|c|c|c|}
\hline \multirow[b]{2}{*}{ Variable } & \multicolumn{4}{|c|}{ Pre-intervention } & \multicolumn{4}{|c|}{ Post-intervention } \\
\hline & $\begin{array}{l}\text { Min } \\
(\%) \\
\end{array}$ & $\begin{array}{l}\text { Max } \\
(\%)\end{array}$ & $\begin{array}{l}\text { Mean } \\
(\%)\end{array}$ & $\begin{array}{l}\text { Standard } \\
\text { Deviation }\end{array}$ & $\begin{array}{l}\text { Min } \\
(\%)\end{array}$ & $\begin{array}{l}\text { Max } \\
(\%)\end{array}$ & $\begin{array}{l}\text { Mean } \\
(\%)\end{array}$ & $\begin{array}{l}\text { Standard } \\
\text { Deviation }\end{array}$ \\
\hline SL & 80.00 & 100.00 & 92.00 & 10.95 & 100.00 & 100.00 & 100.00 & 0 \\
\hline VSM.3 & 66.60 & 100.00 & 73.28 & 14.94 & 100.00 & 100.00 & 100.00 & 0 \\
\hline VSM.4 & 66.60 & 100.00 & 79.96 & 18.29 & 66.60 & 100.00 & 93.32 & 14.94 \\
\hline NVSM.3 & 100.00 & 100.00 & 100.00 & 0 & 66.60 & 100.00 & 93.32 & 14.94 \\
\hline NVSM.4 & 33.33 & 100.00 & 73.31 & 27.90 & 66.60 & 100.00 & 86.64 & 18.29 \\
\hline PSRI.RE & 84.00 & 92.00 & 88.00 & 2.83 & 84.00 & 96.00 & 92.00 & 4.90 \\
\hline PSRI.LE & 88.00 & 96.00 & 92.00 & 2.83 & 80.00 & 96.00 & 91.20 & 6.57 \\
\hline STWN.RE & 20.00 & 60.00 & 42.40 & 15.39 & 72.00 & 88.00 & 81.60 & 7.27 \\
\hline STWN.LE & 12.00 & 72.00 & 42.4 & 22.91 & 52.00 & 92.00 & 77.60 & 15.13 \\
\hline DD.RE & 88.75 & 96.25 & 93.11 & 2.86 & 60.00 & 95.00 & 85.00 & 14.58 \\
\hline DD.LE & 70.00 & 95.00 & 87.17 & 10.73 & 80.00 & 95.00 & 91.00 & 6.27 \\
\hline SSW.RE & 70.00 & 96.25 & 82.75 & 12.07 & 57.5 & 97.5 & 79.50 & 15.15 \\
\hline SSW.LE & 40.00 & 92.50 & 70.50 & 24.01 & 35.00 & 95.00 & 73.72 & 23.22 \\
\hline PSI.RE.-10 & 90.00 & 100.00 & 96.00 & 5.48 & 60.00 & 100.00 & 86.00 & 16.73 \\
\hline PSI.LE.-10 & 90.00 & 100.00 & 94.00 & 5.48 & 70.00 & 100.00 & 86.00 & 15.17 \\
\hline PSI.RE.-15 & 70.00 & 100.00 & 84.00 & 11.40 & 60.00 & 90.00 & 78.00 & 13.04 \\
\hline PSI.LE.-15 & 80.00 & 100.00 & 86.00 & 8.94 & 60.00 & 100.00 & 76.00 & 15.17 \\
\hline DPT.T.H.3 & 20.00 & 100.00 & 60.00 & 40.00 & 30.00 & 100.00 & 76.67 & 40.41 \\
\hline DPT.T.N.3 & 30.00 & 100.00 & 63.33 & 35.12 & 50.00 & 100.00 & 83.33 & 28.87 \\
\hline DPT.T.H.4 & 0.00 & 70.00 & 40.00 & 36.06 & 10.00 & 80.00 & 40.00 & 36.06 \\
\hline DPT.T.N.4 & 10.00 & 100.00 & 56.67 & 45.09 & 40.00 & 100.00 & 60.00 & 34.64 \\
\hline DPT.M.H & 46.60 & 56.50 & 51.55 & 7.00 & 43.33 & 60.00 & 51.665 & 11.79 \\
\hline DPT.M.N & 50.00 & 80.00 & 65.00 & 21.21 & 30.00 & 45.00 & 37.50 & 10.61 \\
\hline DCVT.RE & 37.50 & 50.00 & 43.33 & 3.67 & 20.83 & 45.83 & 30.83 & 10.33 \\
\hline DCVT.LE & 25.00 & 45.84 & 32.50 & 7.33 & 8.33 & 41.66 & 24.06 & 9.08 \\
\hline
\end{tabular}

Legend: Min: minimum, Max: maximum, SL: sound location, VSM.3: verbal sequential memory of three sounds; VSM.4: verbal sequential memory of four sounds; NVSM.3: non-verbal sequential memory of three sounds; NVSM.4: non-verbal sequential memory of four sounds; PSRI: percentual speech recognition index; RE: right ear; LE: left ear; STWN: speech test with white noise; DD: dichotic digit test; SSW: Staggered Spondaic Word; PSI: Pediatric Speech Intelligibility in Brazilian Portuguese; 0: signal-to-noise ratio zero; -10: signal-to-noise ratio -10; -15: signal-to-noise ratio 15; HDP.MH:musiek- humming duration pattern; NDT.MN: Musiek-naming duration test; DPT.T.H.3: Taborga duration pattern - humming of three sounds; DPT.T.N.3: Taborga duration pattern - naming of three sounds; DPT.T.H.4: Taborga duration pattern humming of four sounds; DPT.T.N.4:

Taborga duration pattern naming four sounds; DCVT: dichotic consonant vowel test; RGDT: random gap detection test

There was an improvement in performance for the tests of sound localization, memory for verbal sounds with three and four stimuli, speech recognition test in the right ear, speech test with white noise bilaterally, duration pattern test Taborga version [19] with three and four stimuli for both the humming and naming tasks, and for four stimuli, only in 
the naming task. To verify whether the impressions of the descriptive analysis would be confirmed, comparisons were made before and after speech therapy intervention, using the Wilcoxon test (Table 6).

Table 6 P-values of comparisons before and after speech therapy intervention in the behavioral assessment of central auditory processing

\begin{tabular}{|c|c|}
\hline Variables & p-value \\
\hline RGDT_POST - RGDT_PRE & 0.500 \\
\hline SL_POST - SL_FA & 0.157 \\
\hline VSM.3_POST - VSM.3_PRE & $0.046^{*}$ \\
\hline VSM.4_POST - VSM.4_PRE & 0.157 \\
\hline NVSM.3_POST - NVSM.3_PRE & 0.317 \\
\hline NVSM.4_POST - NVSM.4_PRE & 0.180 \\
\hline PSRI.RE_POST - PSRI.RE_PRE & 0.258 \\
\hline PSRI.LE_POST - PSRI.LE_PRE & 0.705 \\
\hline STWN.RE_POST - STWN.RE_PRE & $0.042^{*}$ \\
\hline STWN.LE_POST - STWN.LE_PRE & 0.080 \\
\hline DD.RE_POST - DD.RE_PRE & 0.138 \\
\hline DD.LE_POST - DD.LE_PRE & 0.588 \\
\hline SSW.RE_POST - SSW.RE_PRE & 0.500 \\
\hline SSW.LE_POST - SSW.LE_PRE & 0.891 \\
\hline PSI.RE-10_POST - PSI.RE.-10_PRE & 0.197 \\
\hline PSI.LE-10_POST - PSI.LE.-10_PRE & 0.194 \\
\hline PSI.RE.-15_POST - PSI.RE.-15_PRE & 0.408 \\
\hline PSI.LE.-15_POST - PSI.LE-15_PRE & 0.102 \\
\hline DPT.T.H.3_POST - DPTH3_PRE & 0.180 \\
\hline DPT.T.N.3_POST - DPTN3_PRE & 0.180 \\
\hline DPT.T.H.4_POST - DPT.H.4_PRE & 1.000 \\
\hline DPT.T.N.4_POST -DPT.N.4_PRE & 0.655 \\
\hline DPT.M.H_POST - DPT.M.H_PRE & 0.655 \\
\hline DPT.M.N_POST - DPT.M.N_PRE & 0.180 \\
\hline DCVT.FA_POST - DCVT.FA_PRE & 0.893 \\
\hline
\end{tabular}

Legend: RGDT: random gap detection test; SL: sound location, VSM.3: verbal sequential memory of three sounds; VSM.4: verbal sequential memory of four sounds; NVSM.3: non-verbal sequential memory of three sounds; NVSM.4: non-verbal sequential memory of four sounds; PSRI: percentual speech recognition index; RE: right ear; LE: left ear; STWN: speech test with white noise; DD: dichotic digit test; SSW: Staggered Spondaic Word; PSI: Pediatric Speech Intelligibility in Brazilian Portuguese; 0: signal-to-noise ratio zero; -10: signal-to-noise ratio -10; -15: signal-to-noise ratio 15; DPT.M.H:musiek- humming duration pattern; PT.M.N: Musiek-naming duration test; PTD.T.H.3: Taborga duration pattern - humming of three sounds; DPT.T.N.3: Taborga duration pattern - naming of three sounds; DPT.T.H.4: Taborga duration pattern humming of four sounds; DPT.T.N.4: Taborga duration pattern naming of four sounds; DCVT: dichotic consonant vowel test; POST: post-intervention; *statistically significant result

The inferential analysis showed a statistical difference for the memory test for verbal sounds in sequence for three sounds and speech test with white noise in the right ear, when comparing the results before and after speech therapy intervention. 
In order to visualize the individual performance of all subjects participating in the research, a chart with qualitative categorization (normal and altered) was elaborated in relation to the reference criteria of the behavioral assessment of central auditory processing, in the moments before and after speech therapy intervention (Table 7)

Table 7 Summary of qualitative analysis of behavioral assessment of central auditory processing after intervention

\begin{tabular}{|c|c|c|c|c|c|c|}
\hline & & Subject 1 & Subject 2 & Subject 3 & Subject 4 & Subject 5 \\
\hline \multirow[t]{2}{*}{ RGDT } & Pre & Altered & Altered & Altered & Normal & Normal \\
\hline & Post & Normal & Normal & Altered & Normal & Normal \\
\hline \multirow[t]{2}{*}{ SL } & Pre & Normal & Normal & Normal & Normal & Normal \\
\hline & Post & Normal & Normal & Normal & Normal & Normal \\
\hline \multirow[t]{2}{*}{ VSM } & Pre & Normal & Normal & Normal & Normal & Normal \\
\hline & Post & Normal & Normal & Normal & Normal & Normal \\
\hline \multirow[t]{2}{*}{ NVSM } & Pre & Normal & Normal & Normal & Altered & Normal \\
\hline & Post & Normal & Normal & Normal & Normal & Normal \\
\hline \multirow[t]{2}{*}{ STWN } & Pre & Altered & Altered & Altered & Altered & Altered \\
\hline & Post & Altered & Normal & Normal & Normal & Normal \\
\hline \multirow[t]{2}{*}{ PSI } & Pre & Normal & Normal & Normal & Normal & Normal \\
\hline & Post & Normal & Normal & Normal & Normal & Normal \\
\hline \multirow[t]{2}{*}{ DD } & Pre & Normal & Altered & Altered & Normal & Normal \\
\hline & Post & Normal & Altered & Normal & Normal & Normal \\
\hline \multirow[t]{2}{*}{ SSW } & Pre & Altered & Altered & Altered & Altered & Normal \\
\hline & Post & Altered & Altered & Altered & Normal & Normal \\
\hline \multirow[t]{2}{*}{ DCVT } & Pre & Altered & Normal & Normal & Altered & Altered \\
\hline & Post & Altered & Normal & Normal & Altered & Altered \\
\hline \multirow[t]{2}{*}{ DPT } & Pre & Altered & Altered & Altered & Altered & Altered \\
\hline & Post & Normal & Altered & Altered & Altered & Normal \\
\hline
\end{tabular}

Legend: RGDT: random gap detection test; LL: sound location, VSM: verbal sequential memory; NVSM: non-verbal sequential memory; PSRI: percentual speech recognition index; STWN: speech test with white noise; DD: dichotic digit test; SSW: Staggered Spondaic Word; PSI: Pediatric Speech Intelligibility in Brazilian Portuguese; DPT: duration pattern test; PRE: pre-intervention; POST: post intervention

As presented in Chart 1, even after the proposed intervention, no child showed adequate results in all tests performed.

\section{Discussion}

Several individuals who suffer mild head injuries that apparently do not cause physical sequelae have underlying cognitive or auditory processing changes that can go unnoticed and underreported [3]. If these changes are common in patients with mild trauma, in individuals who are more severely injured, as in cases of moderate and severe TBI, these changes are more evident, especially when it occurs in subjects who are in a frank learning process, such as children.

Observing the descriptive (Table 1) and inferential (Table 2) analysis of the LLAEP components, using tone burst, despite an improvement in electrophysiological responses due to the reduction of latency of some components and an increase in P2 amplitude (Table 1), when comparing the pre and post intervention moments, these differences were only relevant for the N1 latency in the left ear (Table 2).

The registration of the LLAEP components reflects the cortical electrophysiological activity, and a significant reduction in the latency of the N1 component, using tone bursts, may indicate that there was a change in the auditory pathways due to the speech therapy intervention process. Results of improvement in LLAEP with tone burst stimulus have already been reported in studies with children with communication disorders undergoing speech-language rehabilitation, but not in children with brain trauma. The authors reported that the changes observed in auditory potentials are due to structural and/or functional changes in the central nervous system in the face of the speech-language intervention process [21]. 
In order to verify whether the type of eliciting stimulus influenced the results of LLAEP, in individuals post TBI, in addition to the evaluation with tone burst stimulus, the evaluation with complex stimuli was performed.

Examining the descriptive (Table 3) and inferential (Table 4) analysis of the LLAEP components, using complex stimuli, there was a reduction in the latency of the N1, P2 and N2 components and for the latency of the P3 component only in the right ear, when comparing the moments before and after speech therapy intervention. These results reinforce the hypothesis of improvement of LLAEP compared to speech therapy intervention [21] and allows us to infer that the speech eliciting stimuli were more sensitive to demonstrate this improvement.

In this study, it can be seen that the individuals showed more evident improvement in the LLAEP components with complex stimulus than with the LLAEP elicited with tone burst, corroborating the findings of the other study [22], in which better latencies and amplitudes in LLAEP with complex stimulus (speech) in relation to LLAEP with tone burst. The discrepancy between LLAEP results with tone burst and complex stimulus can be justified by the difference in processing the type of stimulus (non-verbal $\mathrm{x}$ verbal) by the nervous system [23, 24].

For the behavioral assessment of central auditory processing, the results of descriptive statistics suggested improvement in some tests, before and after speech therapy intervention (Table 5), but inferential analysis confirmed the statistical difference only for the memory test for verbal sounds in sequence for three sounds and for the speech test with white noise on the right ear (Table 6), revealing an improvement in the auditory skills of simple temporal ordering and auditory closure. The improvement in the results of some behavioral tests observed in this study corroborates a previous study carried out in post-TBI patients [18].

When analyzing the individual qualitative results (Chart 1), it can be noted that most subjects presented results compatible with the normality patterns, pre and post intervention, for the special auditory tests that assess the auditory skills of sound localization and verbal and non-verbal. Such procedures constitute the simplified assessment of central auditory processing in individuals without brain impairment, however, limiting the assessment of auditory processing to these procedures is not enough, reinforcing the idea that patients who suffered mild TBI may show more subtle or invisible difficulties, requiring an in-depth investigation, especially behavioral assessments that reflect the functioning of individuals in different situations [25].

The performance of all subjects in the PSI test was also adequate in both evaluation moments, and in the analysis of the ability of auditory closure, evaluated by the speech test with white noise, $80 \%$ of the subjects presented adequate results after speech therapy intervention, however, for the more complex and/or special tests that involve dichotic listening, there was not enough improvement in performance to the point of modifying the qualitative analysis of the result (Chart 1). It is known that language is a superior cortical function that depends on an anatomical structure to develop, which in patients who suffered TBI does not occur in the same way as in patients who do not have an injury [26].

The results obtained showed that the proposed intervention was not sufficient for a more robust impact on behavioral assessment, revealing the need for a more specific and exclusive auditory approach to central auditory processing, such as formal auditory training.

The divergence between the electrophysiological and behavioral results obtained may be due to the characteristics of the subjects selected for the study. Some post-TBI individuals have an inability to maintain attention and show deficits in processing speed, which can affect the response to behavioral hearing tests [27],which makes it important to assess hearing function using electrophysiological tests. It is worth mentioning that the evaluations must be complementary, since the electrophysiological evaluation using the LLAEP assesses the processing of acoustic information [28] and behavioral tests, the functional response that the individual has to this information.

Further studies should be carried out with this population, since no studies were found in the literature on children who suffered TBI, especially with this design.

Even with the diversity of injuries due to TBI, it would be advisable to carry out studies with a larger sample, as children are at the development and neural plasticity peak, scenarios that favor intervention.

Another point to be raised is if intervention should be performed first, language or specifically auditory, or both at the same time, since neurological injury can compromise both. 


\section{Conclusion}

After the speech therapy intervention program in individuals with TBI, it was observed:

Reduction of the latency of the N1 component in the left ear, in the LLAEP with tone burst.

Reduction of the latencies of the components N1, P2 and N2 in the right and left ears, and for the latency of the component P3 only in the right ear, in the LLAEP with complex stimuli.

Performance improvement in behavioral tests of central auditory processing of memory for verbal sounds in sequence for three sounds and speech with white noise on the right ear.

\section{Compliance with ethical standards}

\section{Acknowledgments}

To Conselho Nacional de Desenvolvimento Científico e Tecnológico (CNPq) for research productivity grants number $131636 / 2015-4$

\section{Disclosure of conflict of interest}

All of the authors declare that they have all participated in the design, execution, and analysis of the paper, and that they have approved the final version. Additionally, there are no conflicts of interest in connection with this paper, and the material described is not under publication or consideration for publication elsewhere.

\section{References}

[1] Braga FM, Ferraz FAP. Traumatismo crânio-encefálico. In: Prado FC, Ramos J, Valle JR, organizadores. Atualização terapêutica: manual prático de diagnóstico e tratamento. São Paulo: Artes Médicas; 1995; p. 728-30.

[2] Löhr Junior A Conduta frente à criança com trauma craniano. J Pediatr. 2002; 78(supp1):S40-S47.

[3] Colucci, Dennis A AuD, MA Mild Traumatic Brain Injury, The Hearing Journal. 2015; 68(8):38-40.

[4] Bergemalm PO, Lyxell B. Appearances are deceptive? Long-term cognitive and central auditory sequelae from closed head injury. Int J Audiol. 2005; 44(1):39-49.

[5] Marangoni AT, Gil D. Avaliação comportamental do processamento auditivo pré e pós treinamento auditivo formal em indivíduos após traumatismo cranioencefálico. Audiol Commun Res. 2014; 19(1):33-9.

[6] Kraus N, Krizman J An Auditory Perspective on Concussion. Audiology Today 2018; 30 (3):15-21.

[7] Melo JRT, Lemos Júnior LP, Matos LP. Principais causas de trauma craniencefálico na cidade de Salvador, Bahia, Brasil. Arq Bras Neurocir.2005; (24):93-97.

[8] Pinheiro FH, Capellini SA. Treinamento auditivo em escolares com distúrbio de aprendizagem. Pro-Fono R Atual Cient. 2010; 22(1):49-54.

[9] Silva LG, Vitório MG, Pedrini J, Lopes RM. Avaliação de crianças com distúrbio do processamento auditivo antes e após terapia fonoaudiológica.Distúrb Comum. 2009; 21(3):351-363.

[10] Musiek FE, Schochat E. Auditory training and central auditory processing disorders: a case study. Semin Hear.1998; 19(4):357-365.

[11] Carvalho ICCM, Saraiva IS. Perfil das vítimas de trauma atendidas pelo serviço de atendimento móvel de urgência. R Interd. 2015; 8(1):137-148.

[12] Geneva, 18-21 June 1991. Geneva: World Health Organization; 1991. Available from: http://www.who.int/iris/handle/10665/58839

[13] Lloyd LL, Kaplan H. Audiometric interpretation: a manual o basic audiometry. Baltimore: University Park Press; 1978; (94):16-7.

[14] Jasper HH. The ten twenty electrode system of the international federation. (1958) Electroencephalogr Clin Neurophysiol. 1958; (10):371-5. 
[15] Alonso R, Schochat E A eficácia do treinamento auditivo formal em crianças com transtorno de processamento auditivo (central): avaliação comportamental e eletrofisiológica. Braz J Otorhinolaryngol. 2009; 75(5):726-32.

[16] Pereira LD, Schochat E. Testes Auditivos Comportamentais para Avaliação do Processamento Auditivo Central. Barueri: Pró Fono; 2011.

[17] Taborga-Lizarro MB. 1999. Processos temporais auditivos em músicos de Petrópolis. In: Pereira LD, Schochat E. E. Testes auditivos comportamentais para avaliação do processamento auditivo central. Barueri (SP): Pró-Fono; 2011. Protocolo 15. Teste de Padrão de Frequência (TPF) Melódico e Teste de Padrão de Duração (TPD) Melódico.

[18] Musiek FE, Baran JA, Shinn J. Assessment and remediation of an auditory processing disorder associated with head trauma. J Am Acad Audiol. 2004; 15(2):117-32.

[19] Corazza MCA. Avaliação do Processamento Auditivo Central em adultos: testes de padrões tonais auditivos de freqüência e teste de padrões tonais auditivos de duração. Tese, Universidade Federal de São Paulo, São Paulo, Brasil. 1998

[20] Ávila CRB, Kida ASB, Carvalho CAF. 2013. Intervenção Fonoaudiológica nos Transtornos de Leitura e Escrita: abordagem multidimensional. In: Dislexia. Novos Temas, Novas Perspectivas. Wak, São Paulo, Brasil.

[21] Leite RA, Wertzner HF, Matas CG. Potenciais evocados auditivos de longa latência em crianças com transtorno fonológico. Pró-Fono R Atual Cient. 2010; 22(4):561-6

[22] Godoy CCF. Avaliação comportamental e eletrofisiológica do processamento auditivo em crianças e adolescentes que sofreram traumatismo cranioencefálico. [Masters thesis]. São Paulo: Universidade Federal de São Paulo; 2016.

[23] Martin BA, Tremblay KL, Korczack P. Speech evoked potentials: from the laboratory to the clinic. Ear Hear.2008; 29(3):285-313.

[24] Massa CGP, Rabelo CM, Matas CG, Schochat E, Samelli AG. P300 with verbal and nonverbal stimuli in normal hearing adults. Braz J Otorhinolaryngol. 2011; 77(6):686-690.

[25] Dennis M, Hetherington R. Plasticity for Recovery, Plasticity for Development: Cognitive Outcome in Twins Discordant for Mid-Childhood Ischemic Stroke. Child Neuropsychology. 2004; 10(2):117-28.

[26] Duarte N, Vasconcelos MA, Batalha I. Alterações adquiridas da linguagem na infância. 2011. Revista da SPMFR.2011; 20 (1):45-50.

[27] Koshimori, Yuko; Johns, Kadeen; Green, Robin E.A. A guide for hearing healthcare providers to characteristics of traumatic brain injury. Hear J. 2009; 62(11):17-18, 20, $22-23$.

[28] Almeida RP, Matas CG. Potenciais auditivos de longa latência em crianças desnutridas. Codas. 2013; (25)5:40712. 